\title{
Modeling of transformer-rectifier sets for the energization of electrostatic precipitators using Modelica
}

Nannestad, Mads; Bidoggia, Benoit; Zhang, Zhe; Zsurzsan, Tiberiu-Gabriel; Skriver, Kasper

Published in:

Proceedings of the 13th International Modelica Conference

Link to article, DOI:

10.3384/ecp19157221

Publication date:

2019

Document Version

Peer reviewed version

Link back to DTU Orbit

Citation (APA):

Nannestad, M., Bidoggia, B., Zhang, Z., Zsurzsan, T-G., \& Skriver, K. (2019). Modeling of transformer-rectifier sets for the energization of electrostatic precipitators using Modelica. In Proceedings of the 13th International Modelica Conference (pp. 221-228). Linköping University Electronic Press. https://doi.org/10.3384/ecp19157221

\section{General rights}

Copyright and moral rights for the publications made accessible in the public portal are retained by the authors and/or other copyright owners and it is a condition of accessing publications that users recognise and abide by the legal requirements associated with these rights.

- Users may download and print one copy of any publication from the public portal for the purpose of private study or research.

- You may not further distribute the material or use it for any profit-making activity or commercial gain

- You may freely distribute the URL identifying the publication in the public portal 


\title{
Modeling of transformer-rectifier sets for the energization of electrostatic precipitators using Modelica
}

\author{
Mads Nannestad $^{1,2} \quad$ Benoit Bidoggia $^{1} \quad$ Zhe Zhang $^{2} \quad$ Tiberiu-Gabriel Zsurzsan $^{2} \quad$ Kasper Skriver $^{1}$ \\ ${ }^{1}$ FLSmidth A/S, Denmark, bebi@flsmidth.dk \\ ${ }^{2}$ Department of Electrical Engineering, Technical University of Denmark, Denmark
}

\begin{abstract}
Electrostatic precipitators (ESPs) are important parts of many industrial plants. They require high-voltage power supplies. In this paper, transformer/rectifier sets, a particular type of power supplies for the energization of ESPs, are presented and modeled using Modelica. The models have been validated with measurements from existing plants.

Keywords: Modelica, power supply, electrostatic precipitator, ESP
\end{abstract}

\section{Introduction}

Industrial plants-like coal-fired power plants and plants for the production of steel, pulp and paper, and cementneed to satisfy low and strict emission levels of pollutants in the emitted flue gases. One method to reduce the emission of solid pollutants suspended in gas streams is the use of electrostatic precipitators (ESPs) (Fig. 1). In ESPs, the particles of pollutants are electrically charged and pass through a strong electric field. The charged particles moving within the gas stream are therefore deflected towards collecting plates, to which they stick (Fig. 2). To create the ions that are required to charge the particles and to sustain the required strong electric field, high-voltage power supplies are required. ESPs are normally internally subdivided in electrically isolated sections, which are independently energized and controlled. Different topologies of power supplies which can be used to energize ESPs exist. One of them, also the most traditional, is called transformer/rectifier (T/R) set. T/R sets can be single phase or three phase (von Stackelberg, 2013). The aim of this paper is to model open-loop controlled, single- and three-phase T/R sets coupled to ESPs.

To understand the importance of the voltage shape and voltage level energizing ESPs, the concept of collecting efficiency $\eta$ is introduced and defined as

$$
\eta=\frac{\dot{m}_{\mathrm{c}}}{\dot{m}_{\mathrm{i}}}
$$

where $\dot{m}_{\mathrm{c}}$ is the mass flow of collected particles and $\dot{m}_{\mathrm{i}}$ is the mass flow of incoming particles. The efficiency $\eta$ depends on different geometrical parameters of the ESPlike the physical size and the shape of the electrodes and of the collecting plates-and of different physical parameters of the gas stream-like its density, temperature and velocity.

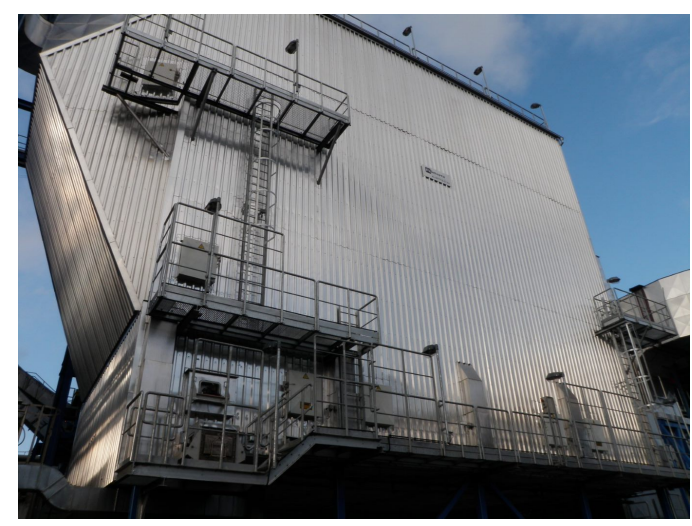

Figure 1. Example of electrostatic precipitator

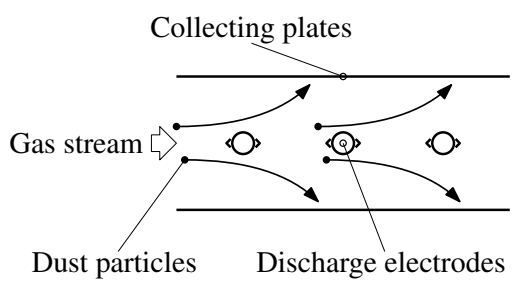

Figure 2. A schematic representation of a portion of an electrostatic precipitator

The influence of the geometrical and physical parameters can be expressed by

$$
\eta=1-e^{-\frac{A}{Q} \omega}
$$

where $A$ is the total collecting area, $Q$ is the flow rate of the gas stream and $\omega$ is called particle migration velocity. Under normal operating conditions, the particle migration velocity is proportional to the power $P_{\mathrm{c}}$ injected into the ESP and can be expressed as

$$
\omega=k \frac{P_{\mathrm{c}}}{A}
$$

where $k$ is a constant that depends on the physical parameters of the particular process (Parker, 1997).

The efficiency $\eta$ can also be expressed more directly in electrical terms by

$$
\eta=1-e^{k_{\eta} \bar{v} \hat{v}}
$$

where $k_{\eta}$ is a constant (Bidoggia et al., 2018), and where $\bar{v}$ and $\hat{v}$ are respectively the mean and peak values of the ESP 


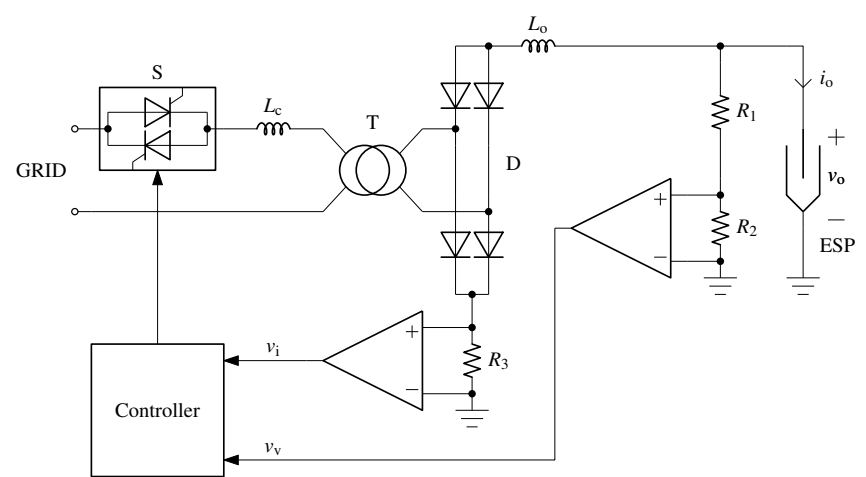

Figure 3. Schematic and block diagram of a single-phase T/R set connected to an electrostatic precipitator (ESP)

voltage. To maximize the collecting efficiency $\eta$ of an ESP, the T/R-set controller acts on the firing angle of thyristors to keep the highest possible mean $(\bar{v})$ and peak $(\hat{v})$ voltage, typically at the limit of the dielectric breakdown voltage of the gas flowing through the ESP.

In this paper, after introducing the main components of single- and three-phase T/R sets (Sec. 2), the Modelica models which have been built will be described (Sec. 3). The simulation results and field measurements are presented and compared in Sec. 4. The conclusions are then presented in Sec. 5.

\section{Energization of ESPs with T/R sets}

In this section, the main components of single- and threephase T/R sets are presented (Fig. 3 and 4). Because of the different output voltage they generate, their usage depends on the particular process of which the ESP is part.

All T/R sets are composed of a step-up transformer (T) and a full-wave rectifier (D). The positive connection of the rectifier is connected to ground to obtain a negative voltage across the ESP. The grid voltage is typically in the range $400 \mathrm{~V}$ to $690 \mathrm{~V}$ and the absolute value of the output voltage $v_{\mathrm{o}}$ can typically be in the range $80 \mathrm{kV}$ to $150 \mathrm{kV}$. The output voltage is measured by the voltage divider made of $R_{1}$ and $R_{2}$. The average value of the output current $i_{\mathrm{o}}$ is typically in the range $800 \mathrm{~mA}$ to $2000 \mathrm{~mA}$ and is measured by the shunt resistor $R_{\mathrm{o}}$. Because sparks can occur inside an ESP under normal operation, an external inductor $\left(L_{\mathrm{c}}\right)$ is inserted to limit the resulting overcurrent; typical per-unit values for $L_{\mathrm{c}}$ are in the range $30 \%$ to $40 \%$ (Parker, 1997). The voltage and current signals, respectively $v_{\mathrm{v}}$ and $v_{\mathrm{i}}$ are measured by the controller, which regulates the firing angle of the thyristors (S) to regulate the power injected to the ESP. On the output side, the inductor $L_{\mathrm{o}}$ prevents highfrequency transients created by sparks from entering the $\mathrm{T} / \mathrm{R}$ set. Because of the high voltage levels, the transformer $\mathrm{T}$, the rectifier $\mathrm{D}$, the resistor $R_{1}$ and the inductors $L_{\mathrm{o}}$ and $L_{\mathrm{c}}$ are immersed in an oil tank. The oil is also used for cooling purposes.

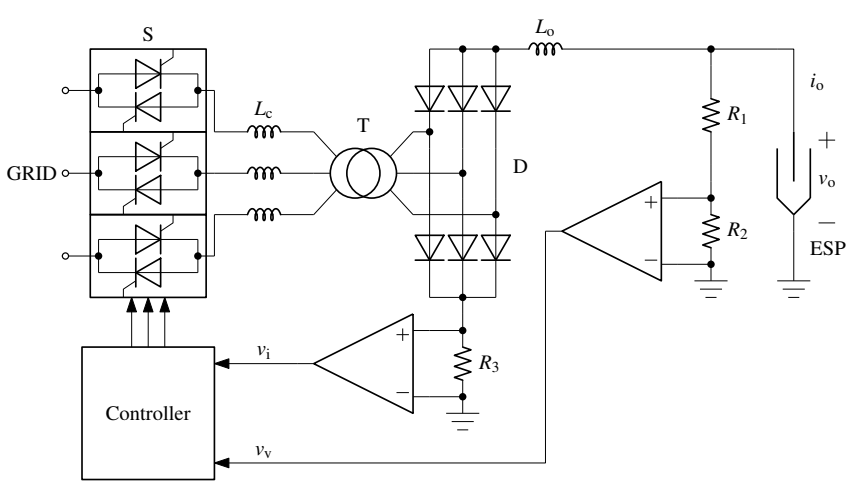

Figure 4. Schematic and block diagram of a three-phase T/R set connected to an electrostatic precipitator (ESP)

\subsection{Single-phase T/R set}

The output voltage waveform of single-phase T/R sets is characterized by a DC component with a superimposed relatively large ripple, with a frequency twice the grid frequency. This type of waveform is typically used in applications for which the resistivity of the particulate to filter falls in the medium-resistivity range $\left(1 \times 10^{7} \Omega \mathrm{m}\right.$ to $\left.5 \times 10^{9} \Omega \mathrm{m}\right)$ (Bidoggia et al., 2018).

\subsection{Three-phase T/R set}

The output voltage waveform of three-phase T/R sets is characterized by a DC component with a negligible ripple, with a frequency six times the grid frequency. This type of waveform is typically used in applications for which the resistivity of the particulate to filter falls in the lowresistivity range $\left(<1 \times 10^{7} \Omega \mathrm{m}\right)$ (Bidoggia et al., 2018).

The transformer is typically connected in a configuration with delta connection at the primary side and star connection at the secondary side.

\section{Modeling}

The Modelica Standard Library and the OpenModelica Connection Editor (OMEdit) have been used to model both single- and three phase T/R sets. The availability of interfaces between different physical domains makes Modelica ideal for modeling multiphysical systems like ESPs. For this work, the following physical domains have been used: electrical, for the power electronics stage; blocks, for the open-loop control of the power electronics stage; thermal, for the calculation of the losses.

In this paper, the model of an ESP has been simplified and represented by an $\mathrm{R}-\mathrm{C}$ circuit, where the values of resistance and capacitance were based on real installations. With the aim of setting the base for a model as representative as possible of real systems, the voltage divider and the current sensor have also been modeled. The voltage divider is designed to provide a voltage ratio $V_{\mathrm{n}} / 10 \mathrm{~V}$, where $V_{\mathrm{n}}$ is the nominal output voltage of the T/R set. The current shunt is designed to provide a current/voltage ratio $I_{\mathrm{n}} / 1 \mathrm{~V}$, where $I_{\mathrm{n}}$ is the nominal output current of the T/R set.

The heating ports of the components from the elec- 


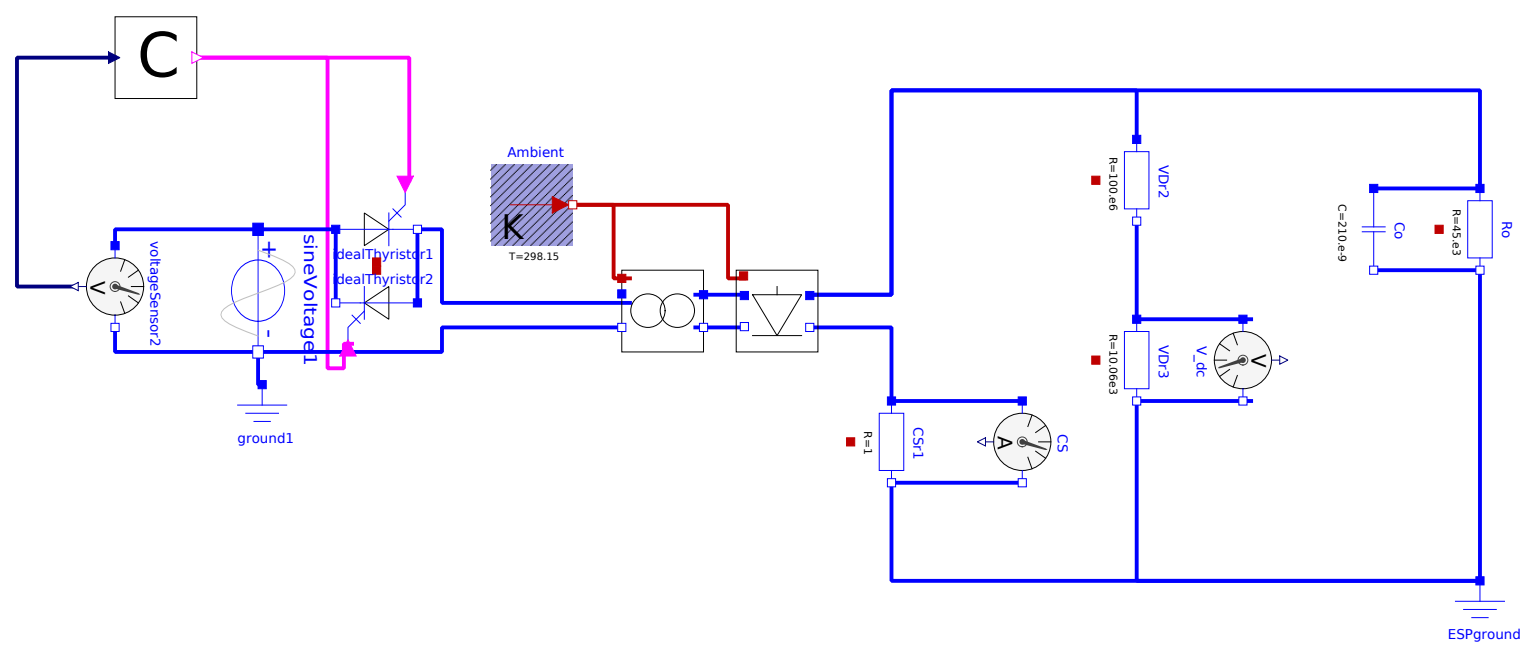

Figure 5. Modelica model of a single-phase T/R set connected to an electrostatic precipitator (ESP)

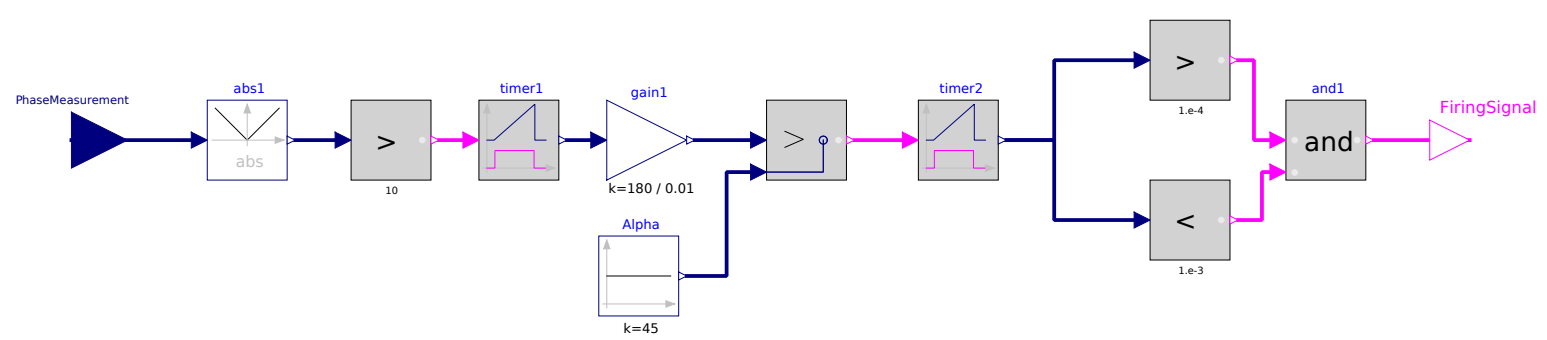

Figure 6. Submodel of a simple open-loop controller for T/R sets

trical domain with losses-such as diodes, resistors and thyristors-have been connected to a fixed ambient temperature of $298.15 \mathrm{~K} \approx 25^{\circ} \mathrm{C}$.

The values of the parameters used in the models are provided by FLSmidth and based on real installations; they are reported in Table 1.

\subsection{Single-phase T/R set}

The derived model of a single-phase T/R set is shown in Fig. 5 with its submodels for the controller, the transformer and the rectifier (Tiller, 2017).

The controller is connected to two ideal thyristors which are fired by boolean signals (Otter et al., 1999). The submodel of the controller is shown in Fig. 6. The controller detects the zero crossing of the grid voltage, represented by an ideal voltage source, and then delays the firing of the thyristors of the diode. The firing delay is given as an angle $(\alpha)$ in the range $0^{\circ}$ to $180^{\circ}$. The firing angle is compared to the output of the chain of the blocks timer1 and gain1, which represents the delay from the zero crossing of the voltage, expressed in degrees. Higher values of $\alpha$ correspond to lower output power. The block timer2 defines the duration of the firing pulse. Because two anti-parallel thyristors are present, the firing signal is given every half period.

The submodel of the full-wave rectifier is shown in
Fig. 7. Because of the high-voltage levels applied to the rectifier, each diode represents a string of diodes connected in series. The three different models of diodes available at the Modelica Standard Library have been investigated (Clauss et al., 2000):

- HeatingDiode: while testing it with a three-phase rectifier and with the heating ports enabled, it seemed to lead to numerical problems;

- Diode2: because the relationship between voltage and current contains exponential expressions, it is not possible to extend the parameters of a diode to a string of diodes by simply manipulating the parameters themselves;

- IdealDiode: the model being linear, the parameters of a string of diodes can be simply derived from the parameters of a diode and the number of diodes in the string.

These models do not include the effect of the reverse recovery (Denz et al., 2014), which is not a concern for this application because of the low switching frequency $(50 \mathrm{~Hz}$ to $180 \mathrm{~Hz})$.

The submodel of the single-phase transformer is shown in Fig. 8 and it is made of the two inductances $L_{1}$ and $L_{\mathrm{m}}$, 
Table 1. Parameters for the models of the single- and three-phase T/R sets

\begin{tabular}{lccccccc}
\hline & $\begin{array}{c}R_{\{1|2| 3\}} \\
{[\mathrm{m} \Omega]}\end{array}$ & $\begin{array}{c}L_{\{1|2| 3\}}[\mathrm{mH}] \\
{[\mathrm{mH}]}\end{array}$ & $\begin{array}{c}L_{\mathrm{m}} \\
{[\Omega]}\end{array}$ & $\begin{array}{c}n \\
{[-]}\end{array}$ & $\begin{array}{c}R_{\mathrm{o}} \\
{[\mathrm{M} \Omega]}\end{array}$ & $\begin{array}{c}C_{\mathrm{o}} \\
{[\mathrm{nF}]}\end{array}$ \\
\hline Single-phase & 25 & 1.8 & 94 & 200 & $1 / 160$ & 45 & 210 \\
Three-phase & 25 & 1.8 & 94 & 94 & $1 / 94$ & 100 & 100 \\
\hline
\end{tabular}

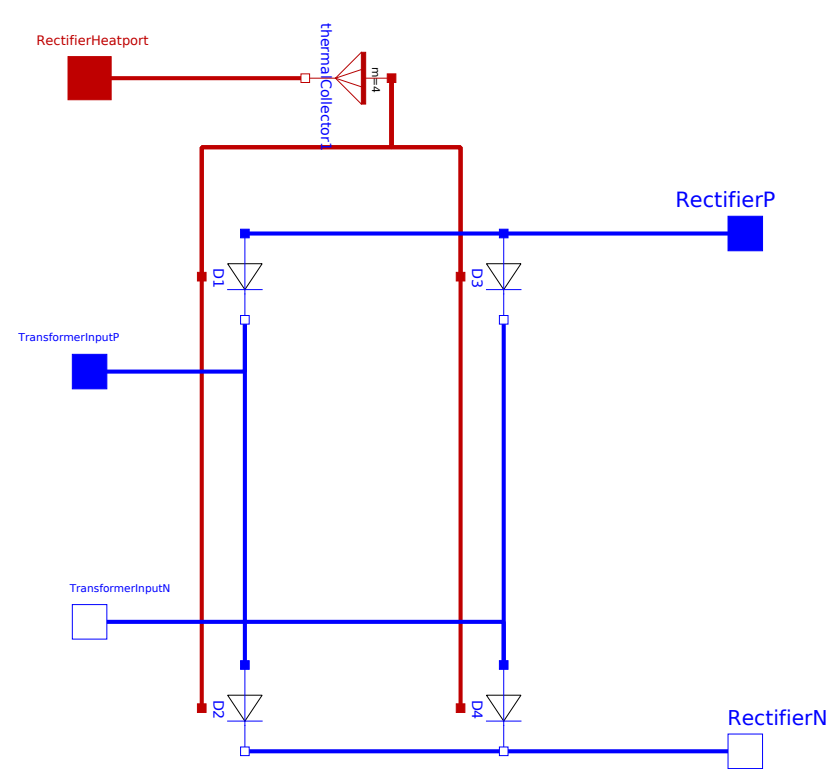

Figure 7. Submodel of the single-phase full-wave rectifier of a T/R set

the two resistances $R_{1}$ and $R_{\mathrm{e}}$, and an ideal transformer with voltage ratio $n=n_{1} / n_{2}$.

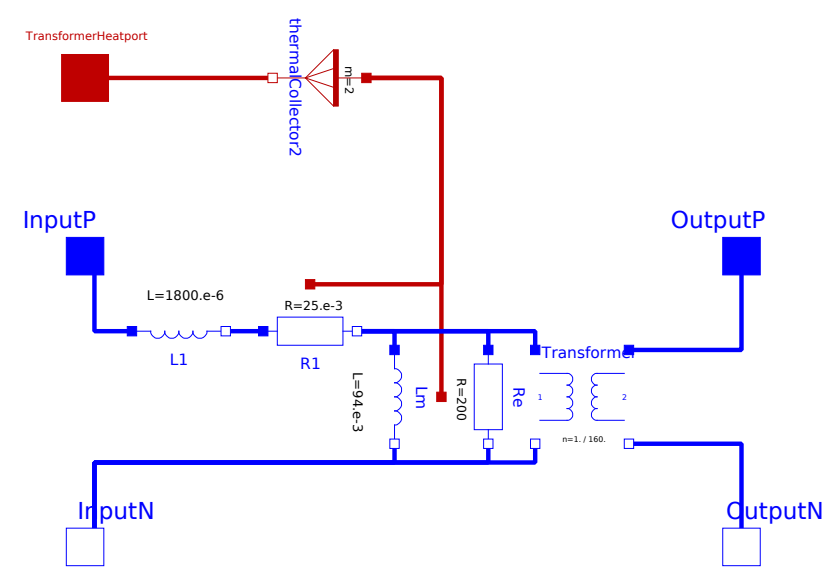

Figure 8. Submodel of the single-phase transformer of a T/R set

The inductance $L_{\mathrm{m}}$ represents the magnetizing inductance of the core of the transformer, while the inductance $L_{1}$ is defined as

$$
L_{1}=L_{1 \sigma}+n^{2} L_{2 \sigma}+L_{\mathrm{c}}+n^{2} L_{\mathrm{o}}
$$

where $L_{1 \sigma}$ is the leakage inductances of the primary side, $L_{2 \sigma}$ is the leakage inductance of the secondary side, $L_{\mathrm{c}}$ is the inductance of the external short-circuit inductor and $L_{\mathrm{O}}$ is the inductance of the output inductor.

The resistance $R_{\mathrm{e}}$ represents the losses in the core of the transformer, while the resistance $R_{1}$ is defined as

$$
R_{1}=R_{1 \mathrm{w}}+n^{2} R_{2 \mathrm{w}}+R_{\mathrm{c}}
$$

where $R_{1 \mathrm{w}}$ is the resistance of the winding of the primary side, $R_{2 \mathrm{w}}$ is the resistance of the winding of the secondary side, and $R_{\mathrm{c}}$ is the resistance of the external short-circuit inductor.

\subsection{Three-phase T/R set}

The derived model of a three-phase T/R set is shown in Fig. 9 with its submodels for the controller, the transformer and the rectifier (Tiller, 2017).

The controller model is the same as for a single-phase $\mathrm{T} / \mathrm{R}$ set but replicated three times.

The choice of the model for the diodes is the same as for the single-phase T/R set. The submodel of the rectifier is shown in Fig. 10.

The submodel of the high voltage transformer is shown in Fig. 11. The inductances and resistances appearing in the model are defined similarly to the homologous ones in the model for the single-phase transformer.

\section{Results}

In this section, the results of the simulation of the models described in Sec. 3 and the results measured on existing plants are presented. Because of the different parameters and the different nominal values of the simulated and real systems, the results have been normalized so that the waveforms of different systems can be compared.

Fig. 12a presents the primary current for both a singleand a three-phase T/R sets connected to an ESP and measured on existing plants. Fig. 12b presents the simulated primary current for both a single- and three-phase T/R set connected to an ESP.

Fig. 12c presents the secondary current and secondary voltage for a single-phase T/R set connected to an ESP and measured on a real plant. Fig. $12 \mathrm{~d}$ presents the simulated secondary current and secondary voltage for a single-phase T/R set connected to an ESP.

Fig. 12e presents the secondary current and secondary voltage for a three-phase T/R set connected to an ESP and 


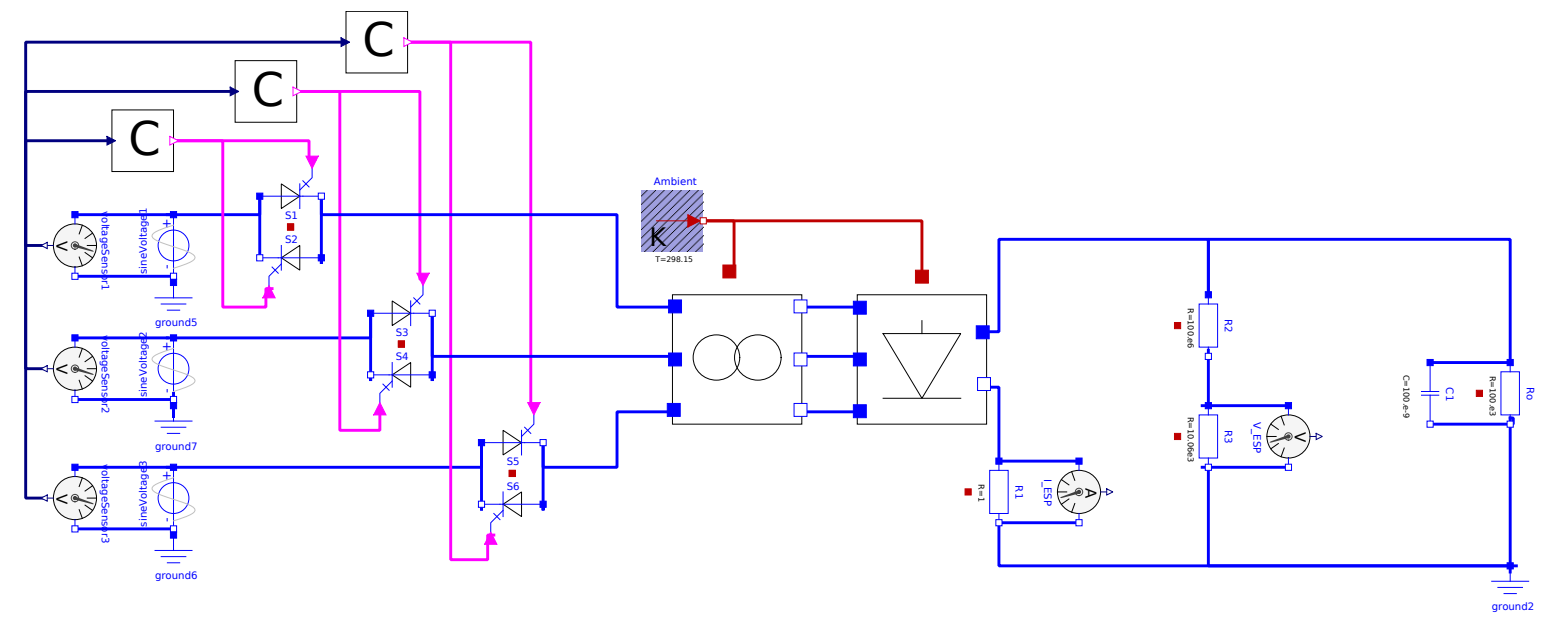

Figure 9. Modelica model of a three-phase T/R set connected to an electrostatic precipitator (ESP)

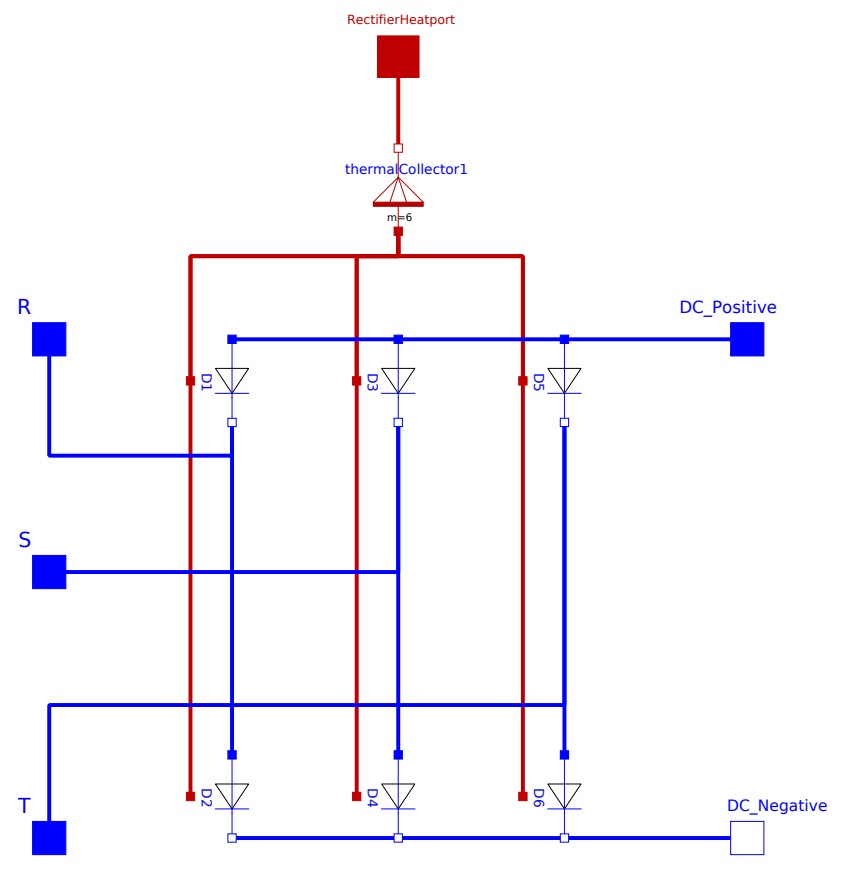

Figure 10. Submodel of the three-phase full-wave rectifier of a T/R set

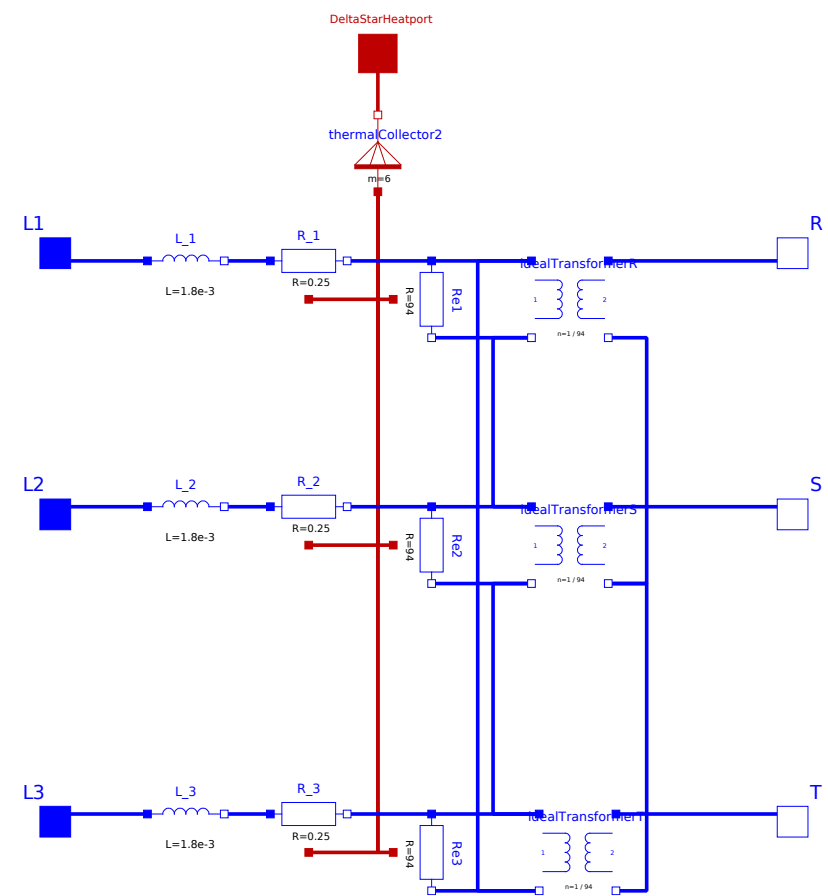

Figure 11. Submodel of the three-phase transformer of a T/R set 
measured on a real plant. Fig. $12 \mathrm{f}$ presents the simulated secondary current and secondary voltage for a three-phase T/R set connected to an ESP. The amplitude of the voltage ripple is significantly smaller than in the case of the singlephase T/R set.

For all waveforms, the shape of the simulated waveforms is in agreement with the shape of the measured waveforms. The minor differences-in the primary current and in the secondary voltage and current-between the simulated and measured results are mostly related to the nature itself of ESPs. These are loads whose parameters are constantly changing as a function of the physical parameters of the gas streams that they are filtering. Thus, also modeling the ESP itself will be of paramount importance, especially in relationship with a closed-loop control system. Other minor differences - like for example in the primary current-are related to other electrical phenomena, which have not been taken into consideration yet, like the switching transients of the thyristors.

\section{Conclusions}

Electrostatic precipitators (ESPs) are important parts of many industrial plants and they require high-voltage power supplies. The goal of the project to which this work belongs is to model a complete ESP system. In this paper, a particular type of power supplies for the energization of ESPs - transformer/rectifier sets- has been presented and simple models have been derived using Modelica. The models have been validated with measurements from existing plants. However, further work will be required, like the derivation of the models of the ESP, of closed-loop controllers and of other topologies of power supplies. The derivation of a complete thermal model for these power supplies is planned.

\section{Acknowledgment}

We thank our colleagues from FLSmidth A/S and DTU, who provided insight and expertise that greatly assisted the research.

\section{References}

Benoit Bidoggia, Mads Kirk Larsen, Karsten Poulsen, and Kasper Skriver. Coromax micro-pulse power supplies (mppss) replace switch-mode power supplies (smpss) at an estonian power plant. In Proceedings 15th International Conference on ESP (ICESP), Charlotte, NC, USA, 9-11 October (2018), 2018.

C. Clauss, A. Schneider, T. Leitner, and P. Schwarz. Modelling of electrical circuits with modelica. In Workshop Modelica, 2000 .

Patrick Denz, Thomas Schmitt, and Markus Andres. Behavioral modeling of power semiconductors in modelica. In 10th International Modelica Conference, 2014.

Martin Otter, Hilding Elmqvist, and Sven Erik Mattsson. Modeling of mixed continuous/discrete systems in modelica. Technical report, 1999.

K.R. Parker, editor. Applied electrostatic precipitation. Chapman and Hall, 1997.

Michael M. Tiller. Modelica by Example - Release v0.5.3-0g4c1367c. 2017.

Josef von Stackelberg. The three-phase power supply for low ripple high voltage in conventional technology. In ICESP XIII, September 2013, Bangalore, India. Rico-Werk, Toenisvorst, Germany, 2013. 


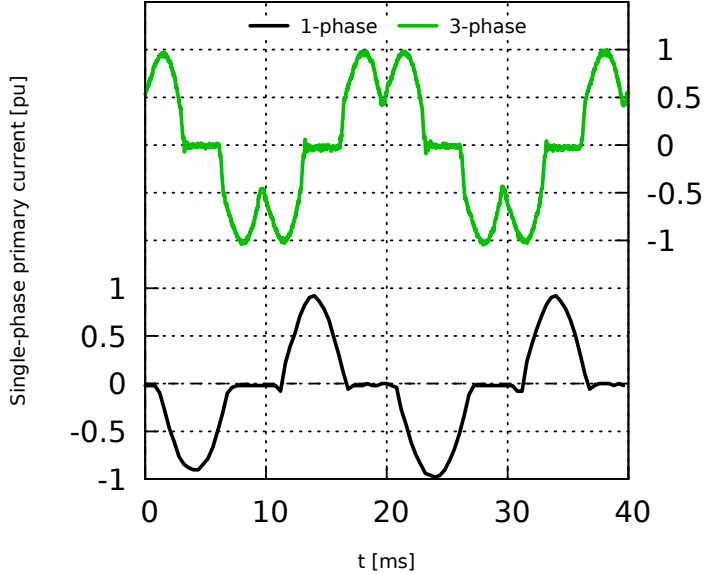

(a) Measured primary current for a single-phase (base current $I_{\mathrm{b}}=170 \mathrm{~A}$ ) and a three-phase (base current $I_{\mathrm{b}}=160 \mathrm{~A}$ ) T/R set

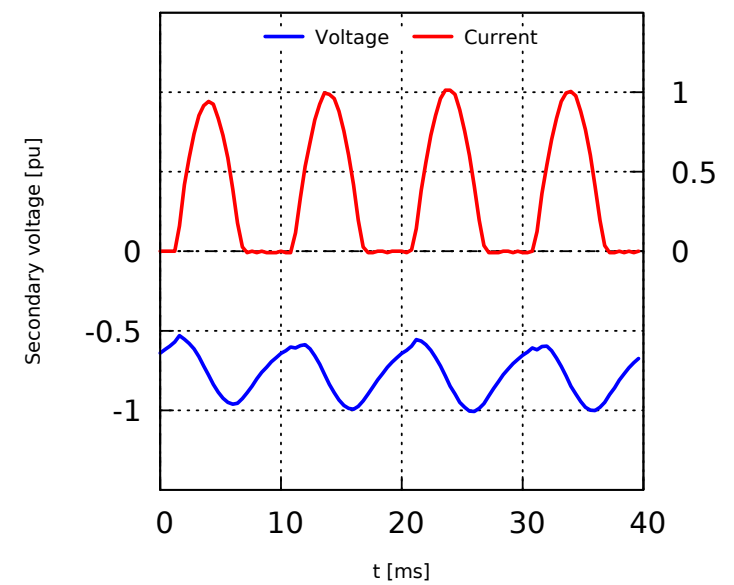

(c) Measured secondary voltage (base voltage $U_{b}=76 \mathrm{kV}$ ) and current (base current $I_{\mathrm{b}}=1800 \mathrm{~mA}$ ) for a single-phase T/R set

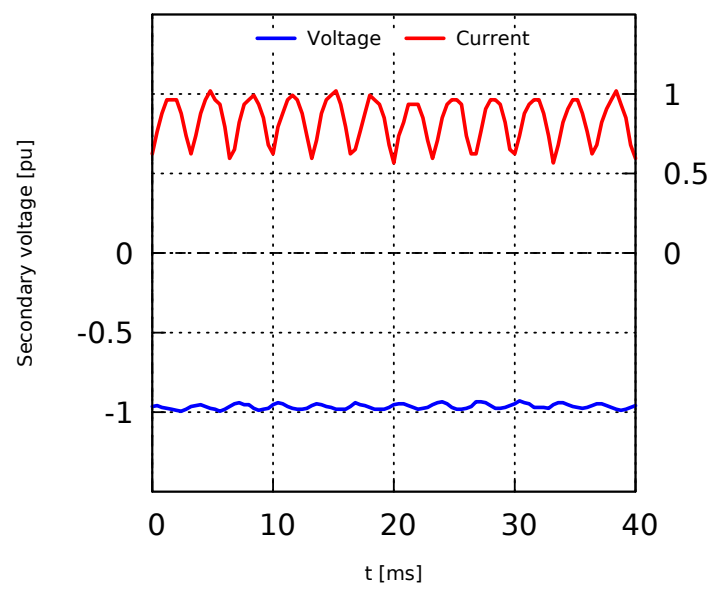

(e) Measured secondary voltage (base voltage $U_{b}=76 \mathrm{kV}$ ) and current (base current $I_{\mathrm{b}}=1200 \mathrm{~mA}$ ) for a three-phase T/R set

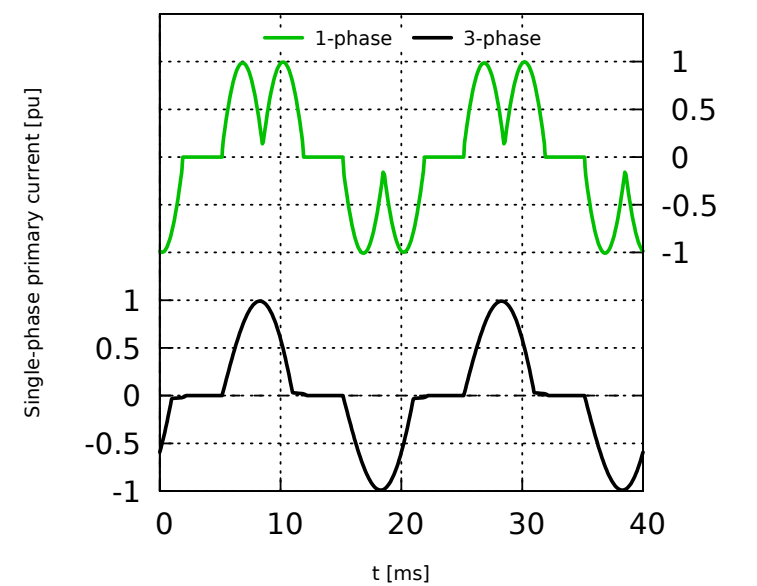

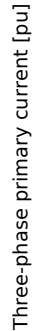

(b) Simulated primary current for a single-phase (base current $I_{\mathrm{b}}=150 \mathrm{~A}$ ) and a three-phase (base current $I_{\mathrm{b}}=85 \mathrm{~A}$ ) T/R set

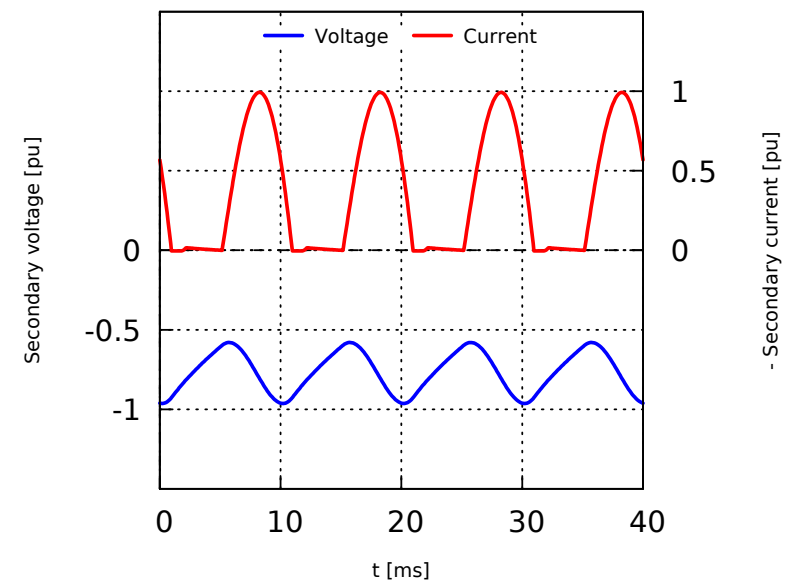

(d) Simulated secondary voltage (base voltage $U_{b}=51 \mathrm{kV}$ ) and current (base current $I_{\mathrm{b}}=2400 \mathrm{~mA}$ ) for a single-phase T/R set

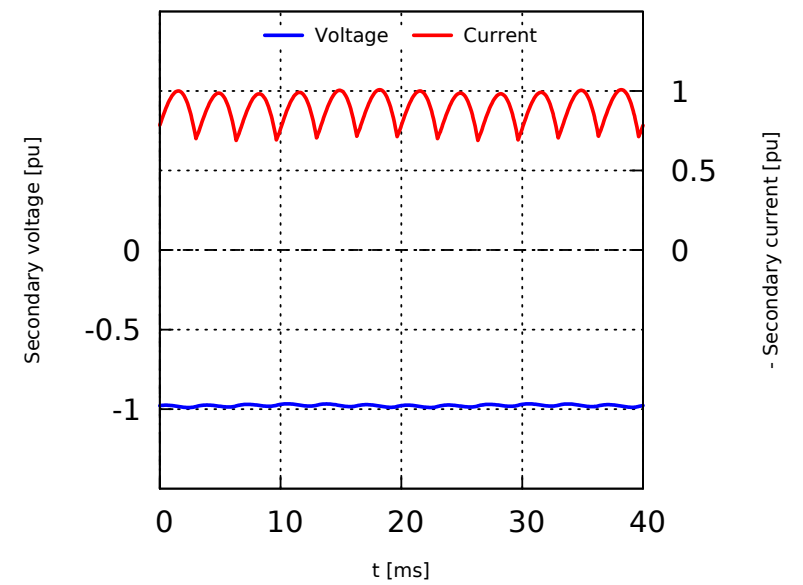

(f) Simulated secondary voltage (base voltage $U_{b}=51 \mathrm{kV}$ ) and current (base current $I_{\mathrm{b}}=800 \mathrm{~mA}$ ) for a three-phase T/R set

Figure 12. Comparison between the main waveforms of measurements and simulation results for single-phase and three-phase T/R sets 